\title{
Evaluation of Emission Pattern of Compression Ignition Engines Fuelled With Blends of Orange Peel Oil Based Biodiesel Using Artificial Neural Network Model
}

\author{
Chukwuemeka Uguba Owora* and Samson Kolawole Fasogbon \\ Department of Mechanical Engineering, University of Ibadan, Nigeria
}

Submission: May 08, 2020; Published: May 20, 2020

*Corresponding author: Chukwuemeka Uguba Owora, Department of Mechanical Engineering, University of Ibadan, Nigeria

\section{Abstract}

It is well established that Orange peeled oil biodiesel (OPOB) is a suitable fuel in Compression Ignition (CI) engines because of its compatible physicochemical properties with diesel. Literature is however sparse on its emission characteristics in CI engines majorly because few investigations have been done due to seemingly difficult and time-consuming experiments. On this strength, this work first carried out experimental investigations on carbon monoxide (CO), unburned hydrocarbon (UHC), oxides of nitrogen (NOX) and smoke of orange peel oil based biodiesel in single cylinder, four stroke CI engine; and afterwards applied the power of artificial neural networks (ANNs) prediction model to predict to the full-scale CO, UHC, NOX, and SMOKE values of the CI engine. Brake load, orange oil-diesel mixture percentages and engine speed were the inputs of the ANN while Levenberg Marquardt (trainlm) and scaled conjugate gradient (trainscg) were the training algorithms to enable better comparative estimation. Performance indicators (correlation coefficient (R), mean absolute percentage error (MAPE) and root mean squared error (RMSE)) were used to compare the predicted and experimental values of the neural network. The ANN trained with Levenberg Marquardt algorithm predicted the emissions with highest accuracy ( $R$ very close to +1 ) and low error rates. The study concludes that ANN is a reliable tool to investigate the emissions profile of a CI engine.

Keyword: Artificial neural network; Training algorithms; ANN performance indicators; Orange peel biodiesel; Emissions; Compression ignition engine

\section{Introduction}

Developments in the transportation sector, agricultural and industrial sectors reveal that fossil fuels play very important role [1]. However, there is increasing demand for alternative fuel such as biodiesel due to the increasing global population, depletion of world fossil fuel reserves, GHG emission, harmful environmental impact and toxic emissions associated with petroleum fuel resources [2-4]. The major contributing factors of negative environment impact of fossil fuels are the emissions of carbon monoxide (CO), smoke, unburned hydrocarbon (UHC), nitrogen oxides (NOx) and particulate matter (PM) pollutants [5]. These problems, especially environmental security, made it necessary for increased research into alternative environmentally friendly and renewable fuels [6,7]. Biofuels from vegetable oil or animal fats have been proposed as a likely alternative to conventional fuels and usage biodiesels from the above sources in a diesel engine represents innovation since it is an oxygenated fuel, possess high cetane number and flash point, it is biodegradable [8], miscible with diesel, sulphur free, compatible with fuel distribution system and can be applied to diesel engine without engine modification [9]. Biodiesel is a fuel of short alkyl esters which are derived from non-fossil sources through catalysed alkaline-based chemical reaction, otherwise called transesterification. The process converts triacylglycerol (TAG) and alcohol into alkyl esters and fatty acid, with glycerol as co-product $[2,9,10]$. The process reduces the viscosity of the oil by the removal and replacement of glycerine in the oil with radicals of the alcohol [11]. The physicochemical properties of biodiesel are comparable with petroleum diesel [12]. Biofuels are associated with food crises and 
land availability since they are derived from food-based crops and lands for agricultural purposes would be allocated to planting of biofuel derived plants [13-17]. Therefore, the use of orange peel which is plant waste to produce biodiesel solves the problem of food-versus-fuel argument. Akpan et al. [18], estimated that the total quantity of orange and orange peel oil produced in Nigeria is 1.626 million tons, and 233,859-485,554 litres per annum, respectively. Global estimation shows that in 2017, orange production rose from 3.2 to 50.2 million metric tons [19]. These results show that waste orange peel would be abundant to handle the population demand for orange peel oil as alternative fuel.

In literature, orange peel oil biodiesel is reported to have been applied in internal combustion engines. Ashok et al. [20] applied orange peel oil of $20 \%$ to evaluate emission performance of a CRDi engine. The evaluation shows that smoke, carbon monoxide and unburned hydrocarbon emissions were lower than those of diesel, while oxides of nitrogen was higher than that of diesel. Ashok et al. [21] investigated the emission effects of $20 \%$ lemon peel oil on CRDI. Smoke, carbon monoxide and unburned hydrocarbon emissions showed significant reduction at all operating conditions while oxides of nitrogen was reduced at low injection pressure of lemon peel oil. Kumar et al. [22] investigated the emissions profile of lemon peel oil methyl ester blends on CI engine. The study showed that carbon monoxide and unburned hydrocarbon increased with increase in percentage of exhaust gas recirculation, while oxides of nitrogen decreased at 10\% EGR.
Ashok et al. [23] made a comparative assessment of orange and lemon peel oil biofuels. The assessment shows that orange peel oil performs better than lemon peel oil but they both have significant reduction in carbon monoxide and unburned hydrocarbon due to their high oxygen content than diesel. However, biofuels emitted higher oxides of nitrogen. Ashok et al. [24] studied the performance and emission values of lemon peel oil on diesel engine. The study observed that with the exception of oxides of nitrogen, lemon peel oil produced lower unburned hydrocarbon, carbon monoxide and smoke due to high oxygen content, Lower LHV and low cetane number. In their study, Purushothaman et al. $[25,26]$ studied the emission characteristics of CI engine operating on diesel-orange oil blends. The investigation shows an increase in emission of oxides of nitrogen and reductions in emissions of smoke, carbon monoxide and unburned hydrocarbon. Manimaran et al. [27] experimentally studied emission of orange peel oil and cotton seed oil blend with petrol in petrol engine. Low carbon monoxide and unburned hydrocarbon emissions were observed as compared to petrol fuel. In all the literatures, the reduced emission profiles were attributed to oxygen content of the orange peel oil, lower low heating value and cetane index, and lean airfuel mixture but there was no attempt to test unblended OPOB. From the reviews, only low percentage blends of OPOB and citrus derived biodiesels were used in the emission studies. It will be interesting to note that $100 \%$ OPOB biodiesels were not applied. Thus, this study is partly focused towards thinning this gap. Table 1 shows the properties of orange peel oil and diesel.

Table 1: Properties of orange peel oil and diesel $[20,26,28]$.

\begin{tabular}{|c|c|c|c|}
\hline Properties & ASTM Method & Orange Peel Oil & Diesel \\
\hline Calorific value KJ $/ \mathrm{kg}$ & D-4809 & 34,650 & 43,000 \\
\hline Density@ $300^{\circ} \mathrm{kg} / \mathrm{lit}$ & D-4052 & 0.8169 & 0.8284 \\
\hline Viscosity @ $40^{\circ} \mathrm{C}, \mathrm{cSt}$ & D-445 & 3.52 & 2.7 \\
\hline Flash point, ${ }^{\circ} \mathrm{C}$ by PMCC method & D-93 & 74 & 52 \\
\hline Fire point, ${ }^{\circ} \mathrm{C}$ by PMCC method & D-2500 & 47 & 49 \\
\hline Cetane Number & D-613 & 21.2 & - \\
\hline Oxygen content & - & & \\
\hline
\end{tabular}

The use of ANN becomes a necessity when application of biodiesel is geared towards commercial implementation. The reason is that optimisation of the best acceptable suitable mixture (biodiesel + diesel) requires strenuous series of experiment which are time consuming, costly and complex to conduct $[29,30]$. ANN has been found to be a powerful tool for predicting complex relations in engineering by establishing the relationship between input and output parameters [31]. In this study, experimental study was conducted on CI engine and the emission profile obtained. The experimental results were employed to train the developed neural network models. In the network, the outputs were the emissions (carbon monoxide, unburned hydrocarbon, oxides of nitrogen and smoke), while the inputs were engine load, speed and blend percentages. ANN is an information system that imitates the human neurological system $[32,33]$. It has the best features among estimation models and the multilayer perceptron (MLP) structure is the most used [34]. The MLP consists three or more layers: an input layer, one or more hidden layer, and an output layer and the neurons are interconnected by linking weights [3539]. All the layers contain neurons which are interconnected. The input layer neurons only transfer information to the hidden layer neurons. In the hidden layer, each neuron makes addition of all the inputs, such that once the summation exceeds activation values, an output is produced. The inputs are transferred to the output layer, and the process may be repeated depending on the number of iterations and error, and a response is obtained. The error is back-propagated into the network until sufficient minimisation is achieved. The error is the difference between predicted value and 
actual value. Sufficiently trained neural network has improved predictive ability [40]. Mathematically, the output is expressed as:

$$
U_{, k}=\sigma\left(\sum_{j=1}^{M} W_{k j} \sigma\left(\sum_{i=0}^{d} W_{j i} X_{i}\right)+B_{i}\right)
$$

Where $\mathrm{U}_{k}$, is the output of the output layer, $\sigma$ is the activation function, $W_{k j}$ weights of the output layer, $W_{i i}$ weights of the hidden layer, $X_{i}$ are the values of the inputs, $B_{i}$ is the value of the bias neuron of the hidden layer.

The summation is transferred by activation or transfer function $f\left(U_{i}\right)$. For any given input, activation flow is transferred from input layer to output layer through hidden layer [41]. Figure 1 shows how ANN computations are performed.

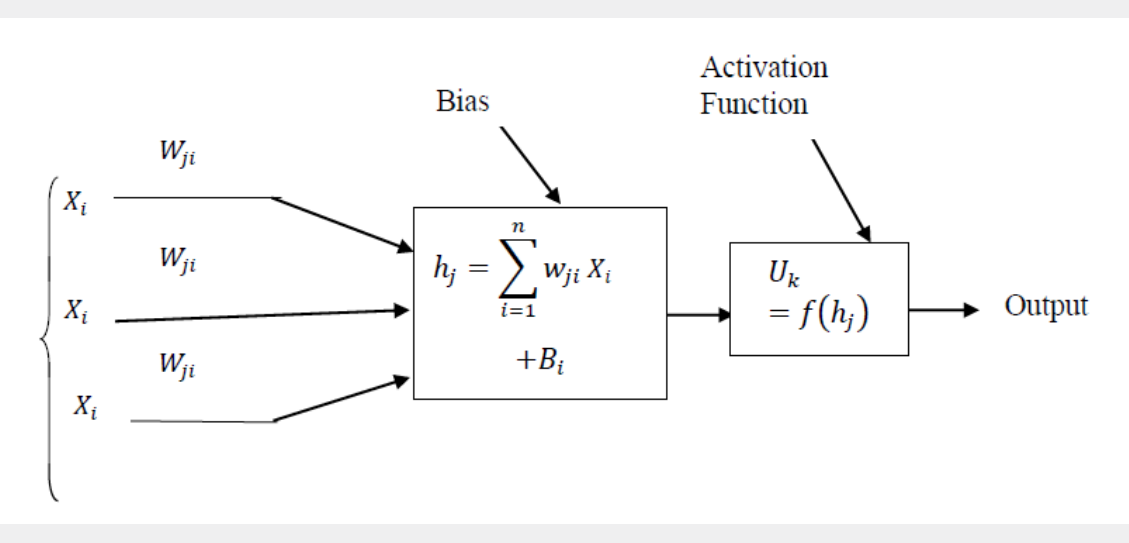

Figure 1: Structure of ANN mode of computation.

Input layer: $d=3$. Hidden layer: $h_{j}=\sigma\left(\sum_{i=0}^{d} W_{i j} X_{i}\right)$ Output layer: $U_{k}=\sigma\left(\sum_{j=0}^{M} W_{k j} y_{i}\right)$.

The neural network has been widely applied in engineering and sciences with great results achieved. Mehra et al. [42], utilised the power of ANN to predict the performance and emission parameters of a turbocharged SI engine fuelled with various HCNG mixtures. Alimissis etal. [43] applied ANN to evaluate air pollutants (CO, NOX, ozone and sulphur oxide) of Metropolitan Anthens in Greece. Kumar et al. [44] predicted the energy consumption of a building using ANN. The network was trained using past history data which represented the behaviour of the building. Zhiqiang et al. [45] predicted the performance and emissions of a single cylinder PFI engine running in blends of butanol-gasoline, using compression ratio, equivalence ratio, blend percentage and engine brake load as input parameters. Nwufo et al. [46] investigated the performance of a single cylinder G200 IMEX spark ignition engine using artificial neural network model approach. The model showed that the Levenberg Marquardt algorithm and logistic sigmoid activation function for a model of structure 4-10-2 provided a sufficiently high prediction accuracy. Argumugam et al. [47] determined the performance and emission of a single cylinder four stroke diesel engine fuelled with blends of rapeseed oil methyl ester using four inputs: blend percentages of the biodiesel, engine load specific fuel consumption and exhaust temperature, and one output: brake thermal efficiency. Emissions of a liquefied petroleum gas (LPG) spark ignition engine has been studied using ANN. The model adopted the back propagation algorithm for the training. The ANN predicted the performance and emission of the engine with very low RMSE, MRE, and high R [48]. Mustafa et al.
[49] used ANN model created using $\mathrm{C}++$ programming language to predict engine performance and exhaust emissions of spark ignition engine.

The crux of the novelty of this paper is the development of ANN models for extensive evaluation of the emission pattern of $\mathrm{CI}$ engine operated on OPOB-fuelled CI engines. The novelty rests on our detailed explanation of the $\mathrm{CI}$ engines ANN models which reflected three input parameters: engine load, engine speed and blend percentages; and four output parameters: CO, UHC, NOX and Smoke. Two distinct cases were considered with respect to number of hidden layer neurons and the types of algorithms used. While we cannot claim novelty of the two algorithms used, their combined application is however novel because it enhances the choice of reliably efficient ANN model for the network estimation. Another novelty of the work is the particular assessment of the emission profiles of unblended orange peel oil biodiesel (OPOB) in $\mathrm{CI}$ engine. Therefore, this paper focused on crossing the existing gap in application of unblended OPOB in CI engines; and also proposed a new method of $\mathrm{CI}$ engine emissions prediction with minimal time and effort.

\section{Materials and Method}

\section{Materials used in the biodiesel production}

The materials used include orange peel, sucrose, urea, distilled water, stirrer, foil paper, watmann No1 filter paper, piece of folded cheese cloth and baker's yeast. Also, we used glass beakers, 
graduated cylinders, conical flask, test tubes, micro pipettes, wash bottles, electronic weighing machine, autoclave, incubator, centrifuge, alchometer hydrometer, thermometer, distillation unit, heating mantle, Distillation, Orange, Peel Oil Fermentation Biodiesel magnetic stirrer with hot plate and water bath. In the characterisation of the orange peel oil biodiesel, bomb calorimeter, viscometer, pour point and cloud point, equipment, flash point and fire point equipment, ethanol, diesel, plastic bottles, funnel and combustion gas analyser were used.

\section{Production of orange peel oil biodiesel}

Preparation of the biodiesel involved pre-treatment in which orange peels were collected from local market orange sellers, separated, washed with clean water, and air dried. After, it was grinded, sieved and put in air tight polythene. This was done to enhance quality of the fermentable starch. Inoculums process was conducted in which chemical additives were prepared. Fermentation process took place afterwards under $20^{\circ} \mathrm{C}-35^{\circ} \mathrm{C}$ in order to maximise biodiesel production. Fermentation begun after the prepared substrate mixed with inoculums thoroughly. After this action, the two processes that followed were filtration of the fermented mixtures with beaker that was covered with cheese cloth and proper distillation of the filtrate using distilling pot and heating mantle. Figure 2 shows the process involved in Orange peel Oil biodiesel production.

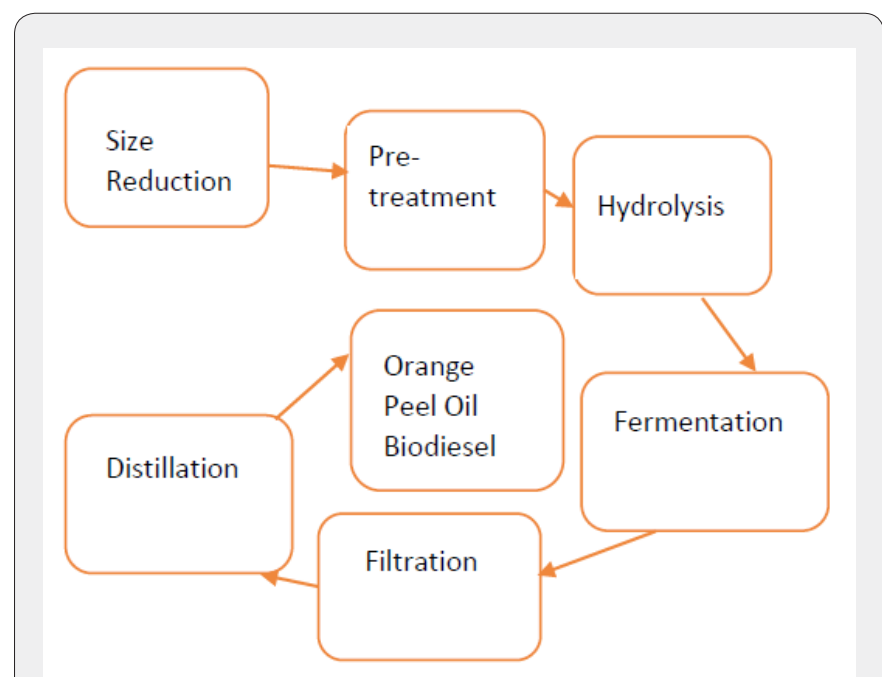

Figure 2: Processes in Orange oil production.

\section{Engine test}

A test rig which comprises a $\mathrm{CI}$ engine, brake dynamometer, combustion gas analyser, biodiesel and diesel fuels, and funnel was set up. Series of tests were conducted using a single cylinder, air cooled, direct injection, diesel engine. The engine was connected to an electrical dynamometer and gas analyser. Blend (diesel + orange peel oil biodiesel) percentages of mixture containing orange peel oil of proportion $10,20,30,40,50,60,70$, 80,90 and 100 percent were prepared. The initial experiment was conducted using neat diesel at different brake loads. After that the engine was subsequently switched over to the various orange peel oil diesel blends. After operating the engine with the blends, the engine was lastly operated on diesel fuel to ensure difficulties are not encountered during subsequent usage. Figure 3 shows the experimental set up, while Table 2 shows the engine specifications.

Table 2: Engine Specification.

\begin{tabular}{|c|c|c|}
\hline $\mathbf{S} / \mathbf{N}$ & Engine Parameter & Value \\
\hline 1 & Rated Power & $4.4 \mathrm{KW}$ \\
\hline 2 & Stoke & $110 \mathrm{~mm}$ \\
\hline 3 & Cylinder Bore & $87.5 \mathrm{~mm}$ \\
\hline 4 & Compression ratio & $17.5: 1$ \\
\hline 5 & Swept Volume & $661 \mathrm{cc}$ \\
\hline
\end{tabular}

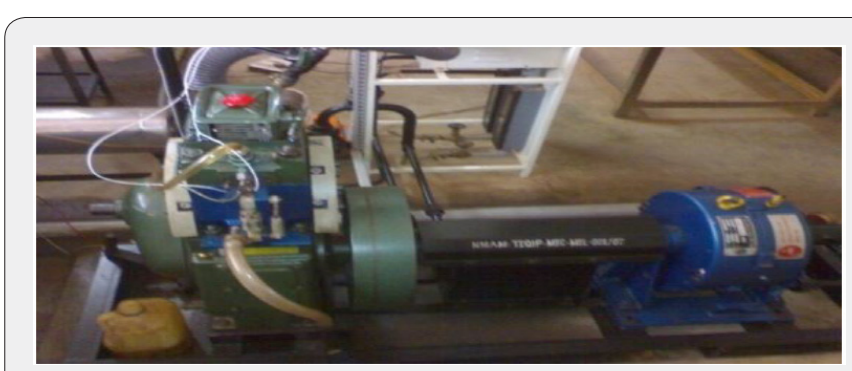

Figure 3: Experimental setup.

\section{ANN Model}

After tabulating the emission profiles, ANN models were developed using the experimental data. The ANN models were executed using MATLAB. The ANN inputs were blend percentages, brake load and the speed; the outputs were emission parameters (carbon monoxide, unburned hydrocarbon, oxides of nitrogen, and smoke). The number of neurons in the hidden layer was continuously interchanged for all chosen training algorithm until a better result was obtained. During the simulation, $70 \%$ of the experimental data were used for training the network, while the remaining $30 \%$ was used testing and validation of the network. Two algorithms were used to execute the task, which include Levenberg-Marquardt (trainlm), and Scaled conjugate gradient (trainscg). This was to ensure that a better estimation was obtained. The network structures were 3-10-4, 3-12-4, and 3-154. This multi-structural approach was to set very good basis for performance comparison.

\section{ANN models performance indicators}

Some statistical parameters are usually employed to evaluate the performance of ANN models. Correlation coefficient R, mean absolute percentage error MAPE, and root mean squared error RMSE, were used to evaluate the performance of the networks. Equations 2-4 shows the performance indicators. 


$$
\begin{aligned}
& R=\frac{\sum_{i=1}^{n}\left(a_{i n}-\tilde{a}_{i n}\right)\left(a_{i j}-\tilde{a}_{i j}\right)}{\sqrt{\sum_{i=1}^{n}\left(a_{i n}-\tilde{a}_{i n}\right)^{2} \cdot \sum_{i=1}^{n}\left(a_{i j}-\tilde{a}_{i j}\right)^{2}}} \\
& M A P E=\frac{1}{n} \sum_{i=1}^{n}\left|\frac{a_{i n}-a_{i j}}{a_{i n}}\right| \times 100 \\
& R M S E=\sqrt{\frac{1}{n} \sum_{i=1}^{n}\left(a_{i n}-a_{i j}\right)^{2}}
\end{aligned}
$$

Results and Discussion

\section{Engine emission evaluation}

\section{Carbon monoxide}

Figure 4 represents the effect of carbon monoxide (CO) emissions with respect to brake power. Carbon monoxide emissions represent partial reaction between carbon and carbon dioxide. Thus, incomplete atomization or carbon dissociation results in CO production. However, we observed that CO emissions were higher at low and partial loads than full brake powers. Contributing factors could be low in-cylinder pressure and temperature resulting from prolonged ignition delay enhanced by delayed combustion during premixing of the fuels and air. Generally, 100\% OPOB, that is B100, produced the least $\mathrm{CO}$ emissions, and all the blends produced lower CO than diesel.

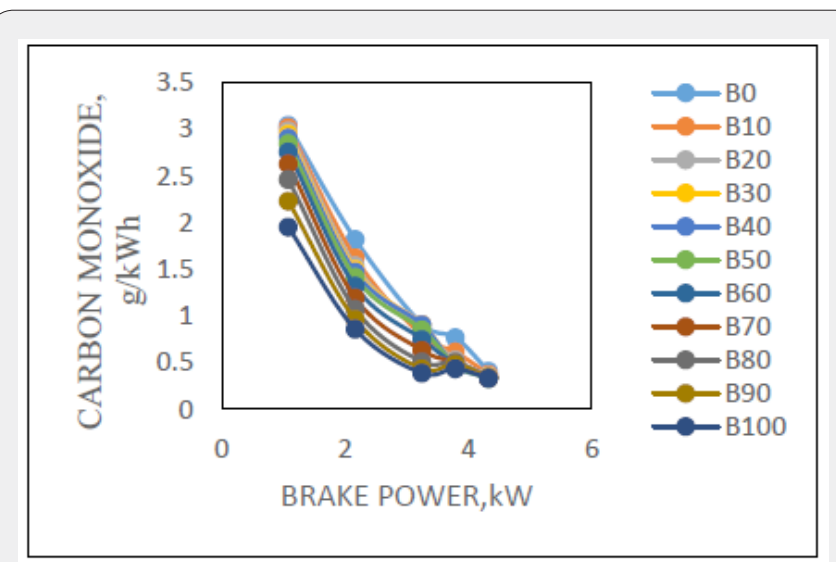

Figure 4: Variation of $\mathrm{CO}$ against brake power.

\section{Unburned hydrocarbon}

Formation of unburned hydrocarbon (UHC) has been linked to the trapping of fuel-air mixture in the parts of the combustion chamber. This makes the mixture to hide from flame. Emissions of the entrapped fuels are called unburned hydrocarbon. Such emissions were lower in OPOB and its blends than diesel. A necessary factor which influences this, could be high oxygen content of OPOB which results to complete combustion. UHC was low at fuel load than partial load. Figure 5 shows the behaviour of UHC with respect to brake power.

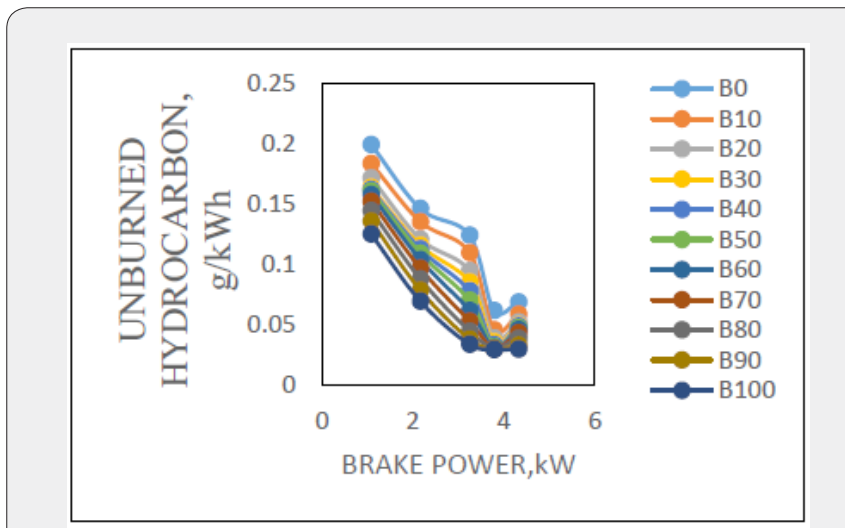

Figure 5: Variation of UHC against brake power.

\section{Oxides of nitrogen}

Oxides of nitrogen (NOX) is influenced by many factors which include in-cylinder temperature, coefficient of excess air, higher combustion temperature and time of occurrence of combustion reaction. Oxygen is associated with higher temperature and excess air, while ignition delay has been associated with cetane number. The lower the cetane number, prolong is the ignition delay, thus longer time for occurrence of combustion. From Table 1, cetane number is lower in OPOB than diesel. By this, we observed that produced lower NOX than OPOB and the blends. Figure 6 shows the relation between NOX and brake power.

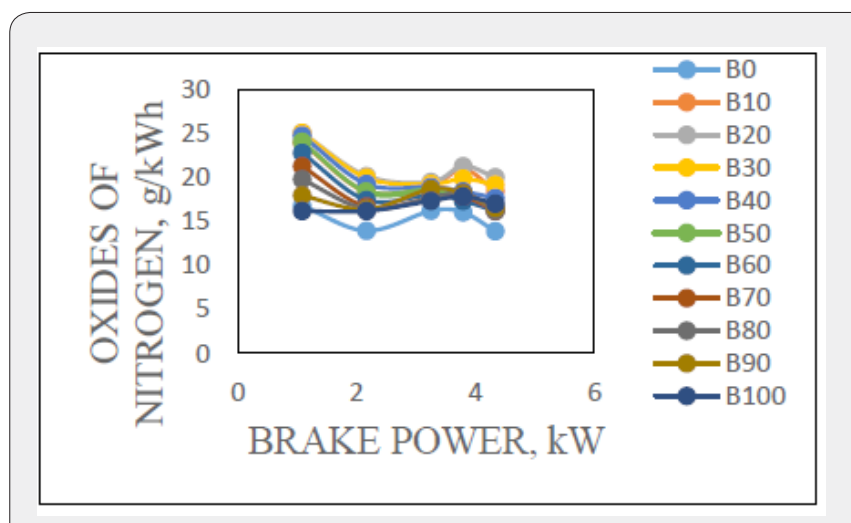

Figure 6: Variation of UHC against brake power.

\section{Smoke}

The variation of smoke with brake power is shown in Figure 7. In contrast, smoke emissions were lower for OPOB and the blended fuels than diesel. A major factor to which this is occurrence is attributed is the higher oxygen content of OPOB and the high aromatic quality of diesel. It was observed that at full load, smoke increased significantly. It has been reported that at full load, there is minimal air-fuel ratio. This results to incomplete combustion of the fuels. However, OPOB and the blended fuels emitted minimal smoke than diesel. 


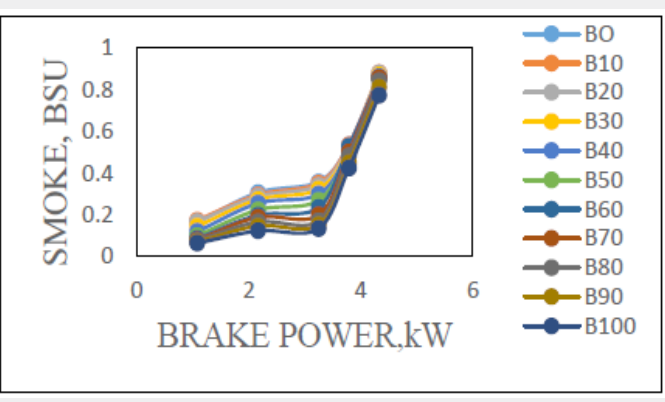

Figure 7: Variation of smoke against brake power.

Evaluation of correlation among parameters sensitivity analysis

After normalisation, another critical step is usually identification of the correlations among the input and output parameters; otherwise called sensitivity analysis. The correlations were evaluated using Pearson correlation which operates in the range of -1 to $+1[50,51]$. Table 3 shows the correlation coefficients among input and output parameters.

Table 3: Parameter correlations - sensitivity of inputs to outputs and output to input.

\begin{tabular}{|c|c|c|c|c|c|c|c|}
\hline & PEB & EL & ES & Co & UHC & NOX & SMOKE \\
\hline PEB & 1 & - & - & -0.166 & -0.185 & 0.259 & -0.079 \\
\hline EL & - & 1 & -0.894 & -0.879 & -0.897 & -0.44 & 0.915 \\
\hline ES & - & -0.894 & 1 & 0.623 & 0.607 & 0.257 & -0.895 \\
\hline CO & -0.166 & -0.879 & 0.623 & 1 & 0.949 & 0.586 & -0.692 \\
\hline UHC & -0.185 & -0.847 & 0.607 & 0.949 & 1 & 0.522 & -0.659 \\
\hline NOX & -0.259 & -0.44 & 0.257 & 0.586 & 0.522 & 1 & -0.385 \\
\hline SMOKE & -0.079 & 0.918 & -0.895 & -0.692 & -0.659 & -0.385 & 1 \\
\hline
\end{tabular}

Useful information can be extracted from the table. The highest correlations among the output parameters are in theorder of engine load (EL), engine speed (ES), and percentage fuel blends (PFB). This equally shows the contribution of each input parameters to the various emissions. The data from experiment, after using Pearson correlation method to test their sensitivity showed that each emission data operating within a range of -1 and +1 has values that largely correlate with the input parameters.

\section{ANN model results for different training algorithms}

The predicted data were compared with the experimental using the performance indicators. During the training, the number of hidden layer neurons was estimated using equation 5 :

$$
N N=\frac{I+O}{2}+\sqrt{s} \pm 5
$$

Where NN is number of hidden layer neurons, $\mathrm{S}$ is number of training data set used in the ANN. I, number of input parameters and $O$ is number of output parameters respectively. The actual number of hidden layer neurons in the ANN training is usually varied by \pm 5 from the solution obtained in eq. (5) [30].

The neural network was trained with two different algorithms (Levenberg Marquardt and Scaled Conjugate Gradient) for better estimation. The results of the performance of the ANN model using the performance indicators is shown below (Table 4).

Table 4: Performance of the ANN model.

\begin{tabular}{|c|c|c|c|}
\hline Training Algorithm & NN & R & RMSE \\
\hline LM & 10 & 0.99922 & 0.4033361 \\
\hline LM & 12 & 0.99927 & 0.40542657 \\
\hline LM & 15 & 0.999605 & 0.1042192 \\
\hline SCG & 10 & 0.99738 & 0.6917297 \\
\hline SCG & 12 & 0.99803 & 0.7040099 \\
\hline SCG & 15 & 0.99353 & 1.0301942 \\
\hline
\end{tabular}

From the table, we see that the Levenberg Marquardt algorithm trained with 15 hidden neurons produced the best result with correlation coefficient value of $\mathrm{R}=0.999605$ and root mean squared error RMSE=0.1042192.

\section{ANN result for carbon monoxide emission}

Using eq. 5 we made selection of 10 to 15 hidden neurons. Table 5 shows the performance of the neural network with regards to CO. The performance values recorded when Levenberg Marquardt algorithm with 15 hidden neurons were adopted show improved result. The MAPE Value was below 10\% i.e. 9.1954\% with a regression value of $\mathrm{R}=0.9881$ and RMSE of 0.1853 . Figure 8 \& 9 show the linear correlation between predicted and experimental results for the two algorithms with different hidden neurons. We observed that the correlation coefficients of Levenberg Marquardt algorithm were close to +1 which indicates stronger relationship. Almost all data points were close to the linear line than those of Scaled Conjugate Gradient. The RMSE values of the Levenberg Marquardt algorithm were relatively lower than those of Scaled Conjugate Gradient.

Table 5: Performance measure of neural network for $\mathrm{CO}$.

\begin{tabular}{|c|c|c|c|c|}
\hline $\begin{array}{c}\text { Training } \\
\text { Algorithm }\end{array}$ & NN & R & MAPE & RMSE \\
\hline LM & 10 & 0.974199 & 18.08934 & 0.204542 \\
\hline LM & 12 & 0.981828 & 14.28251 & 0.164716 \\
\hline LM & 15 & 0.988118 & 9.1954 & 0.185252 \\
\hline SCG & 10 & 0.960359 & 19.24769 & 0.246962 \\
\hline SCG & 12 & 0.939349 & 31.06403 & 0.297207 \\
\hline SCG & 15 & 0.838328 & 31.06403 & 0.469389 \\
\hline
\end{tabular}




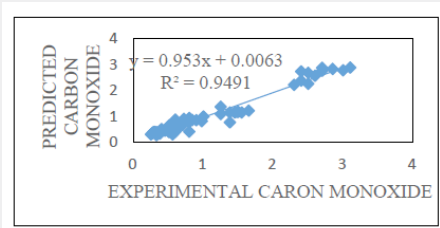

1. $\mathrm{LM}$ for $\mathrm{NN}=10$

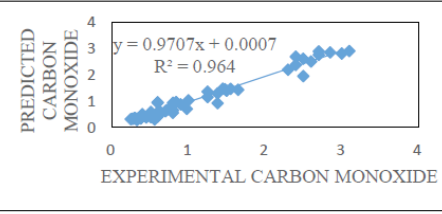

2. $\mathrm{LM}$ for $\mathrm{NN}=12$

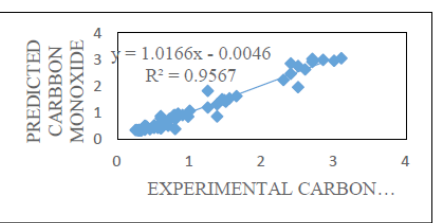

Figure 8: Predicted vs experimental results of Levenberg Marquardt (LM) algorithm with different number of hidden neurons (NN).

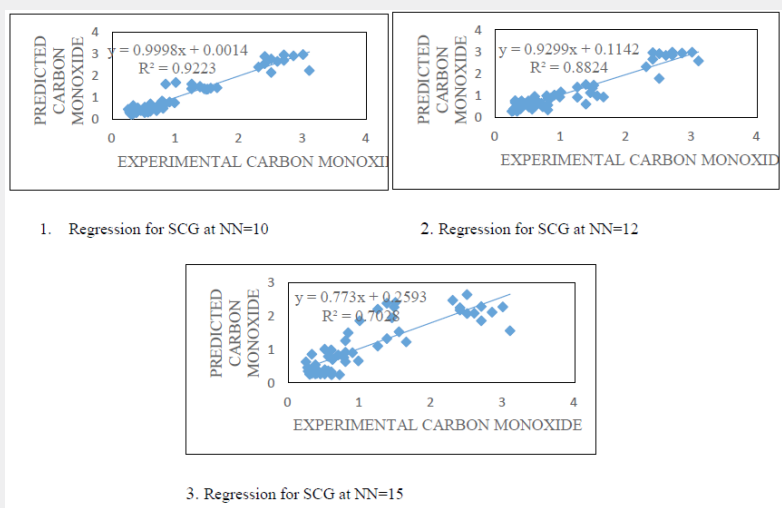

Figure 9: Predicted vs experimental results for Scaled Conjugate Gradient (SCG) algorithm with different number of hidden neurons (NN).

\section{ANN result for unburned hydrocarbon}

Table 6 shows the consistencies between ANN predicted values and the experimental values for UHC. Using equations 2-5 we developed Table 6. The table fixtures how predicted values correlate with experimental values of UHC and the magnitude of the errors between them for the different number of hidden layer neurons. Most of the predicted values were within $\pm 1 \%$ deviation from the experimental results for the trainlm algorithm.

Table 6: Performance measure of neural network for UHC.
The Levenberg Marquardt algorithm produced relatively better correlation coefficient than the Scaled Conjugate Gradient. The MAPE values of LM trained with 15 hidden neurons was below $10 \%$ i.e. $7.76 \%$. Figure $10 \& 11$ show the linear relationship between predicted and experimental results of Levenberg Marquardt algorithm and Scaled Conjugate Gradient with different neurons, respectively. Figure 10 reflected better linearization than Figure 11 , with almost all data points within the linear line especially with $\mathrm{NN}=15$.

\begin{tabular}{|c|c|c|c|c|}
\hline Training Algorithm & NN & R & MAPE (\%) & RMSE (g/kWh) \\
\hline LM & 10 & 0.6199 & 11.90533 & 0.019368582 \\
\hline LM & 12 & 0.8961 & 13.23677 & 0.106854255 \\
\hline LM & 15 & 0.9257 & 7.7578 & 0.163685197 \\
\hline SCG & 10 & 0.7424 & 33.59124 & 0.143261997 \\
\hline SCG & 12 & 0.8664 & 31.68115 & 0.087012947 \\
\hline
\end{tabular}




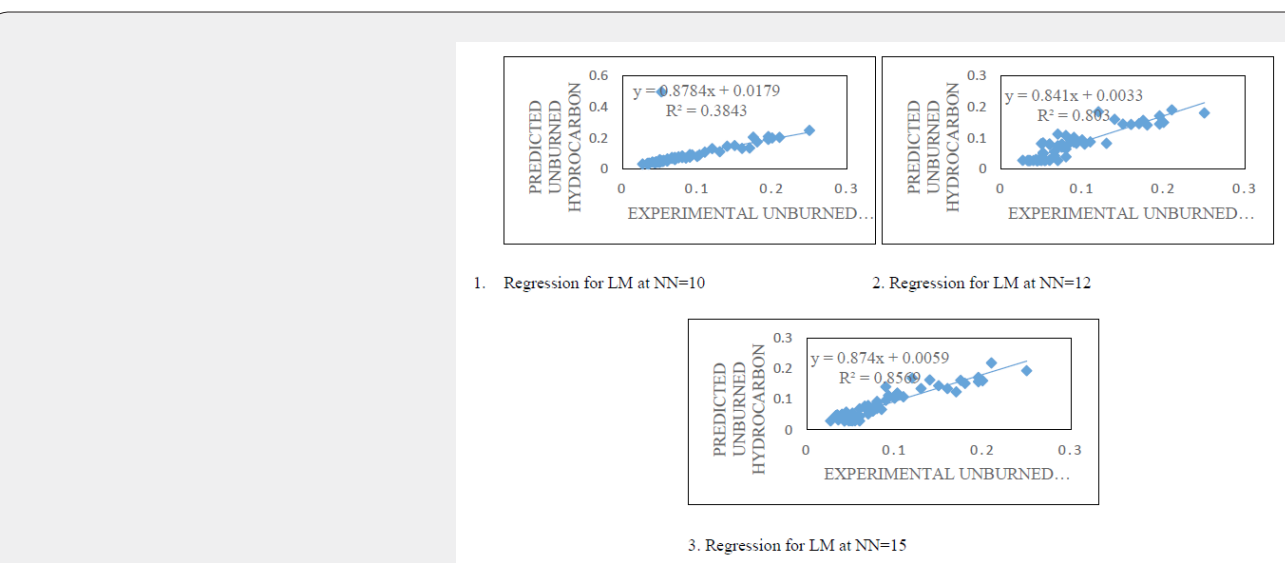

Figure 10: Predicted vs experimental results for Levenberg Marquardt (LM) algorithm with different number of hidden neurons (NN).
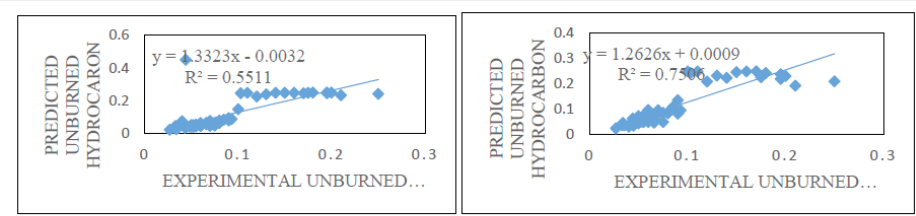

$\begin{array}{ll}\text { 1. Regression for } \mathrm{SCG} \text { at } \mathrm{NN}=10 & \text { 2. Regression for } \mathrm{SCG} \text { at } \mathrm{NN}=12\end{array}$

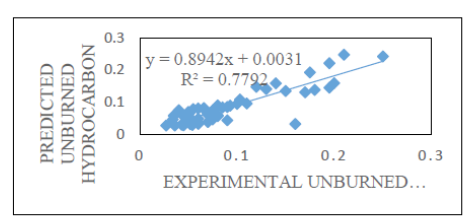

3. Regression for $\mathrm{SCG}$ at $\mathrm{NN}=15$

Figure 11: Predicted against experimental results for Scaled Conjugate Gradient (SCG) algorithm with different number of hidden neurons (NN).

\section{ANN result for oxides of nitrogen}

Table 7 shows the values of networks performance between predicted values and experimental values for NOX. Equations 2-5 were applied in establishing Table 7 . Most of the predicted values were within $\pm 5 \%$ error deviation from the experimental results for the trainlm algorithm as show by the MAPE value. $\mathrm{NN}=15$ produced the least error value of $\pm 2.84 \%$. The correlation coefficients of the two algorithms with different numbers of hidden layer neurons

Table 7: Performance measure of neural network for NOx.

\begin{tabular}{|c|c|c|c|c|}
\hline Training Algorithm & NN & R & MAPE (\%) & RMSE (g/kWh) \\
\hline LM & 10 & 0.9256 & 3.020397 & 1.072452092 \\
\hline LM & 12 & 0.8673 & 4.427958 & 0.745076503 \\
\hline LM & 15 & 0.9691 & 2.8352 & 1.42230271 \\
\hline SCG & 10 & 0.8565 & 5.049066 & 1.044478339 \\
\hline SCG & 12 & 0.927 & 4.617776 & 1.842720543 \\
\hline SCG & 15 & 0.7399 & 8.216469 & \\
\hline
\end{tabular}




\section{International Journal of Environmental Sciences \& Natural Resources}
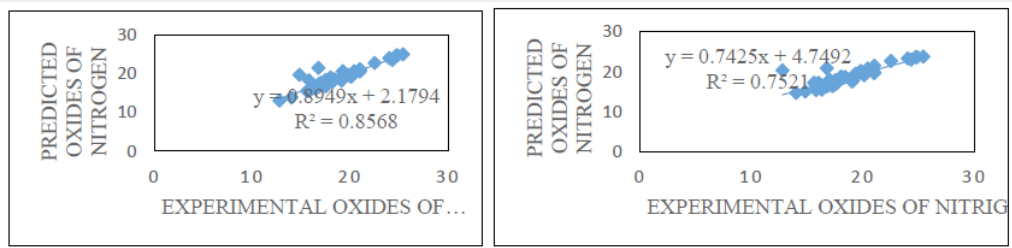

2. Regression for $\mathrm{LM}$ at $\mathrm{NN}=12$

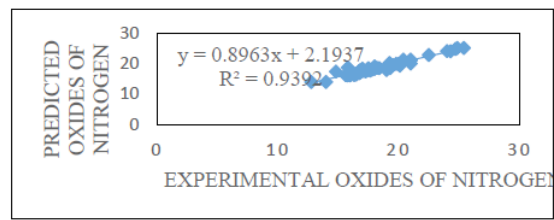

3. Regression for $\mathrm{LM}$ at $\mathrm{NN}=15$

Figure 12: Predicted against experimental results for Levenberg Marquardt (LM) algorithm with different number of hidden neurons (NN).
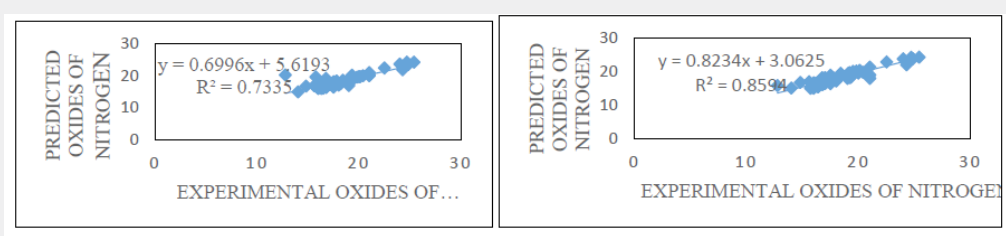

1. Regression for $\mathrm{SCG}$ at $\mathrm{NN}=10$

2. Regression for $\mathrm{SCG}$ at $\mathrm{NN}=12$

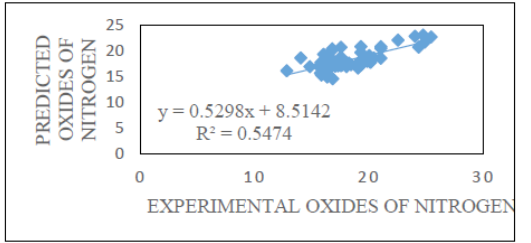

Figure 13: Predicted against experimental results for Scaled Conjugate Gradient (SCG) algorithm with different number of hidden neurons $(\mathrm{NN})$.

\section{ANN result for smoke emission}

The performances of the network models are shown in Table 8 with reference to predicted and experimental values for Smoke emissions. Using equations $2-5$ we established Table 8 . The table shows that the correlation coefficient the two algorithms with hidden layer neurons of 10,12, and 15 were slightly different, with Levenberg Marquardt algorithm trained with NN=15 producing the best regression, $R=0.9764$. Most of the predicted values were Table 8: Performance measure of neural network for SMOKE. within $\pm 10 \%$ error deviation from the experimental results for the trainlm algorithm of $\mathrm{NN}=15$, as shown by MAPE value. The RMSE was generally low. Figure 14 \& 15 show the correlation between predicted and experimental results of the two different algorithms with different neurons. The data points show convergence around the linear line for Figure 14 than those of Figure 15. This shows why the regression values of the Levenberg Marquardt algorithm were higher than those of Scaled Conjugate Gradient.

\begin{tabular}{|c|c|c|c|c|}
\hline Training Algorithm & NN & R & MAPE (\%) & RMSE (BSU) \\
\hline LM & 10 & 0.9653 & 12.5268 & 0.098146 \\
\hline LM & 12 & 0.9347 & 17.30431 & 0.084771 \\
\hline LM & 15 & 0.9764 & 8.8093 & 0.1057 \\
\hline SCG & 10 & 0.7643 & 17.53948 & 0.526884 \\
\hline SCG & 12 & 0.8963 & 20.85696 & 0.271019 \\
\hline SCG & 15 & 0.9488 & 24.75534 & 0.282916 \\
\hline
\end{tabular}



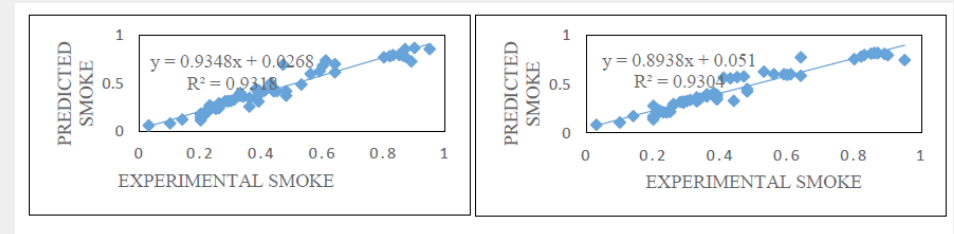

$$
\text { 2. Regression for } \mathrm{LM} \text { at } \mathrm{NN}=12
$$

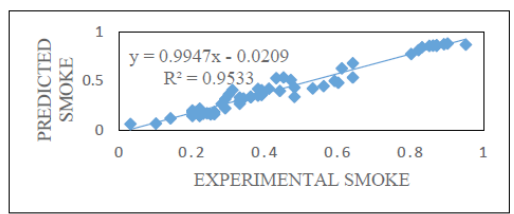

3. Regression for $\mathrm{LM}$ at $\mathrm{NN}=15$

Figure 14: Predicted against experimental results for Levenberg Marquardt (LM) algorithm with different number of hidden neurons (NN).

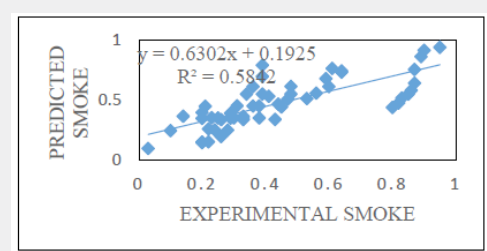

1. Regression for $\mathrm{SCG}$ at $\mathrm{NN}=10$

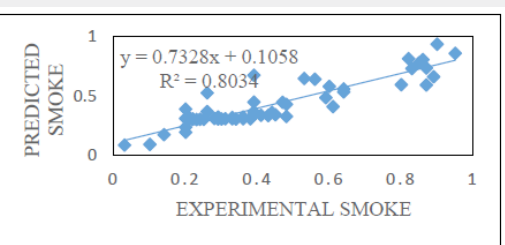

2. Regression for $\mathrm{SCG}$ at $\mathrm{NN}=12$

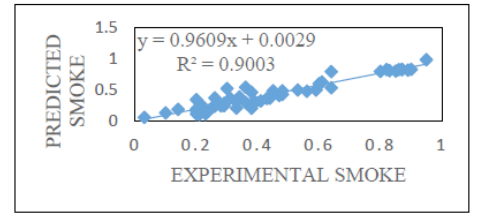

3. Regression for $\mathrm{SCG}$ at $\mathrm{NN}=15$

Figure 15: Predicted against experimental results for Scaled Conjugate Gradient (SCG) algorithm with different number of hidden neurons (NN).

\section{Conclusion}

a) In the study, the application of ANN estimation approach for emissions of CI engine fuelled with biofuel of orange peel oil-diesel blends was conducted after experimental study. The experimental result showed an improved CO, UHC, and Smoke when $100 \%$ OРОВ and its blends were applied. Similarly, CO, UHC, NOX and Smoke were predicted using engine speed, blend percentages of biodiesel, and brake load as inputs. The predicted ANN results were compared with the experimental values using the performance indicators. The following critical conclusions are made from the study:

b) The best regression values for CO, UHC, NOX and Smoke were close to +1 ; indicating a very strong positive relationship between predicted and experimental data. The ANN of feed forward back propagation, Levenberg Marquardt algorithm with $\mathrm{NN}=15$ produced the best results. The computed MAPE and RMSE were very low, which show very high performance of the model.
MAPE values were 9.1954, 11.7578, 2.8352, and 8.80930, while RMSE values were $0.1853,0.0227,0.7451$ and 0.1057 for CO, UHC, NOX and SMOKE respectively.

c) Experimentally, $100 \%$ OPOB produced the least CO, UHC and SMOKE; while OPOB and the blends produced higher NOX than diesel.

d) ANN is a powerful tool for conducting modelling studies for emissions characteristics of $\mathrm{CI}$ engines operated with blended fuels.

\section{Acknowledgement}

The financial support of the Federal Government of Nigeria through the Petroleum Technology Development Fund (PTDF) is acknowledged. It was through the sponsorship this research was conducted. They did not contribute in the design of the research frame work, conducting of experiment and reporting of this work. 


\section{References}

1. Rashedul HK, Masjuki HH, Kalam MA, Ashraful AM, Ashrafur Rahaman SM, et al. (2014) The effect of additives on properties, performance and emission of biodiesel fuelled compression ignition engine. Energy conversion and management 88: 348-364.

2. Pullen J, Saed K(2014) Factors affecting biodiesel engine performance and exhaust emissions -part II: Experimental study. Energy 72: 17-34.

3. Beatrice C, Di Blasio G, Lazzaro M, Cannilla C, Bonura G, et al. Technologies for energetic exploitation of biodiesel chain derived glycerol: oxy-fuels production by catalytic conversion. Applied energy 102: $63-71$.

4. Koc AB, Abdullah M (2013) Performance and NOX emissions of a diesel engine fuelled with biodiesel-diesel-water nano emulsions. Fuel processing technology 109: 70-77.

5. Kumar N, Varun, Chauhan SR (2013) Performance and emission characteristics of biodiesel from different origins: a review. Renewable and sustainable energy reviews 21: 633-658.

6. Roy MM, Wang W, Bujold J (2013) Biodiesel production and comparison of emissions of a DI diesel engine fuelled by biodiesel-diesel and canola oil-diesel blends at high idling operations. Applied energy 106: 198208.

7. SS Hoseini, G Najafi, B Ghobadian, Rizalman Mamat, Nor Azwadi Che Sidik, et al. (2017) The effect of combustion management on diesel engine emissions fuelled with biodiesel-diesel blends. Renewable and sustainable energy reviews 73: 307-331.

8. Mota FAS, Filho JTC, Barreto GA (2019) The nile tilapia viscera oil extraction for biodiesel production in Brazil: an economic analysis. Renewable and sustainable energy reviews 108: 1-10.

9. Pullen J, Saeed K (2014) Factors affecting biodiesel engine performance and exhaust emissions -part 1: review. Energy, pp. 1-16.

10. AE Atabani, AS Silitonga, HC Ong, TM Mahlia, HH Masjuki, et al. (2013) Non-edible vegetable oils: a critical evaluation of oil extraction, fatty acid compositions, biodiesel production, characteristics, engine performance and emissions production. Renewable and sustainable energy reviews 18: 211-245.

11. Cranakci M (2007) Combustion characteristics of a turbocharged DI compression ignition engine fuelled with petroleum diesel fuels and biodiesel. Bioresource technology 98(6): 1167-1175.

12. Leong WH, Lim JW, Lam MK, Uemura Y, Ho YC (2018) Third generation biofuels: a nutritional perspective in enhancing microbial lipid production. Renewable and sustainable energy reviews 91: 950-961.

13. Nigam PS, Singh A (2011) Production of liquid biofuels from renewable resources. Progress in energy and combustion science 37(1): 52-68.

14. Man Lee Lam, Keat Teong Lee (2012) Microalgae biofuels: a critical review of issues, problems and the way forward. Biotechnology advances 30(3): 673-690.

15. Cherubini F (2010) The biorefinery concept: using biomass instead of oil for producing energy and chemical. Energy conversion and management 51(7): 1412-1421.

16. Naik SN, Goud VV, Rout PK, Dalai AK (2010) Production of first and second generation biofuels: a comprehensive review. Renewable and sustainable energy reviews 14(2): 578-597.

17. Voloshin RA, Rodionova MV, Zharmukhamedov SK, Veziroglu TN, Allakhverdiev SI (2016) Review: biofuel production from plant and algae biomass. International Journal of Hydrogen Energy 41(39): 1-17.

18. Akpan P, Ozor P (2014) An estimation of orange oil (Biodiesel) quantity from orange peel in Nigeria. NIIE 2014 conference proceedings.
19. Mueller SA, Anderson JE, Wallinghton TJ (2011) Impact of biofuel production and other supply and demand factors in food price increases in 2008. Biomass bioenergy 35(5): 23-32.

20. Ashok B, Nanthagopal K, Perumal DA, Babu JM, Tiwari A, et al. (2019) An investigation on CRDi engine characteristic using renewable orange-peel oil. Energy conversion and management 180: 1026-1038.

21. Ashok B, Nanthagopal K, Saravanan B, Somasundaram P, Jegadheesan C, et al. (2018) A novel study on the effect lemon peel oil as a fuel in CRDI engine at various injection strategies. Energy conversion and management 172: 517-528.

22. Naresh Kumar A, Brahma Raju K, Srinivas Kishore P, Narayana K (2018) Some experimental studies on effect of exhaust-gas recirculation on performance and emission characteristics of a compression-ignition engine fuelled with diesel and lemon-peel oil blends. Materials today: proceedings 5: 6138-6148.

23. Ashok B, Nanthagopal K, Chaturvedi B, Sharma S, Thundil R (2018) A comparative assessment on common rail direct injection (CRDI) engine characteristics using low viscous biofuel blends. Applied thermal engineering 145: 494-506.

24. Ashok B, Thundil Karuppa Raj R, Nanthagopal K, Krishnan R, Subbarao $R$ (2017) Lemon peel oil - a novel renewable alternative energy source for diesel engine. Energy conversion and management 139: 110-121.

25. Purushathaman K, Nagarajan G (2011) Study of combustion, performance and emission characteristics of a compression ignition engine operating on a diesel-orange oil blended with lower concentrations. International conference on mechanical, automobile and robotic engineering (ICMAR'2011).

26. Purushothaman K, Nagarajan (2008) The effect of orange oil-diesel fuel blends on direct injection diesel engine performance, exhaust emissions and combustion. Thammasat international journal of science and technology 13(4).

27. Manimaran P, Muthurajakumar E, Musakansiva S, Vinoth R (2014) Experimental investigation of the orange peel oil and cotton seed oil blend with petrol as an alternative fuel for petrol engines. International journal of innovative research in science, engineering and technology 3.

28. Deep A, Singh A, Vibhanshu V, Khandelwal A, Kumar N (2013) Experimental investigation of orange peel oil methylester on single cylinder diesel engine. SAE technical paper. p. 10.

29. Cirak B, Demirtas S (2014) An Application of Artificial Neural Network for Predicting Engine Torque in Biodiesel Engine. American Journal of Energy Research 2(4): 74-80.

30. Aydogan H, Altun AA, Ozcelik AE (2011) Performance analysis of a turbocharged diesel engine using biodiesel with back propagation artificial neural network. Energy Education Science and Technology Part A: Energy Science and Research 28: 459-468.

31. Baldinelli A, Barelli L, Bidini G, Bonucci F, Iskenderoglu FS (2019) Regarding solid oxide fuel cells simulation through artificial intelligence: a neural network application. Applied science 9(1): 51.

32. Notton G, Voyant C, Fouilloy A, Duchaud JL, Nivet ML (2019) Some applications of ANN to solar radiation estimation and forecasting for energy applications. Applied science 9(1): 209.

33. Huertas DB, Moyano J, Jimenez CER, Marin D (2019) Applying an artificial neural network to assess thermal transmittance in walls by means of the thermometric method. Applied energy 233-234: 1-14.

34. Mejias RP, Fargallo AP, Bellido CR, Arcas JAP (2017) Comparison of linear regression and artificial neural networks models to predict heating and cooling energy demand, energy consumption and CO2 emissions. Energy 118: 24-36. 
35. Bhowmik S, Panua R, Ghosh SK, Debroy D, Paul A (2018) A comparative study of Artificial Intelligence based models to predict performance and emission characteristics of a single cylinder Diesel engine fueled with Diesosenol. Journal of thermal science and engineering application 10(4): 11.

36. Oguz H, Sarıtas I, Baydan HE (2010) Prediction of diesel engine performance using biofuels with artificial neural network. Expert system application 37(9): 6579-6586.

37. Rezaei J, Shahbakhti M, Bahri B, Aziz AA (2015) Performance prediction of HCCI engines with oxygenated fuels using artificial neural networks. Applied energy 138: 460-473.

38. Kurtgoz Y, Karagoz M, Deniz E (2018) Biogas engine performance estimation using ANN. Engineering Science and Technology, an International Journal 20(6): 1563-1570.

39. Ozgur T, Tuccar G, Ozcanli M, Aydin K (2011) Prediction of emissions of a diesel engine fueled with soybean biodiesel using artificial neural Networks. Energy Educ Sci Technology Part A 27: 301-312.

40. Sharma A, Sahoo PK, Tripath RK, Meher LC (2016) ANN based prediction of performance and emission characteristics of CI engine using polanga as a biodiesel. International Journal of Ambient Energy 37(6): 559-570.

41. Togun NK, Baysec S (2010) Prediction of torque and specific fuel consumption of a gasoline engine by using artificial neural Networks. Applied Energy 87(1): 349-355.

42. Mehra RK, Duan H, Luo S, Rao A, Fanhua Ma (2018) Experimental and artificial neural network (ANN) study of hydrogen enriched compressed natural gas (HCNG) engine under various ignition timings and excess air ratios. Applied energy 228: 736-754.

43. Alimissis A, Philippopoulos K, Tzanis CG, Deligiorgi D (2018) Spatial estimation of urban air pollution with the use of artificial neural network models. Atmospheric Environment 191: 205-213.
44. Kumar R, Aggarwal RK, Sharma JD (2013) Energy analysis of a building using artificial neural network: a review. Energy and buildings 65: 352-358.

45. Liu Z, Zuo Q, Wu G, Li Y (2018) An artificial neural network developed for predicting of performance and emissions of a spark ignition engine fuelled with butanol-gasoline blends. Advances in Mechanical Engineering 10(1): 1-11.

46. Nwufo OC, Okwu MO, Nwaiwu CF, Igbokwe JO, Nwafor OMI, et al (2017) The application of artificial neural network in prediction of the performance of spark ignition engine running on ethanol-petrol blends. International Journal of Engineering and Technologies 12: 1531.

47. Argumugam S, Sriram G, Shankara Subramanian PR (2012) Application of artificial intelligence to predict the performance and exhaust emissions of diesel engine using rapeseed oil methyl ester. Procedia Engineering 38: 853-860.

48. Yusuf T, Saleh KH, Said MA (2011) Engine performance and emission analysis of LPG-SI engine with the aid of artificial neural network. Proc I Mech E Part A: J Power and Energy 225(5).

49. Balki MK, Cavus V, Duran IU, Tuna R, Sayin C (2018) Experimental study and prediction of performance and emission in an SI engine using alternative fuel with artificial neural network. International Journal of Automotive Engineering Technologies 7(1): 58-64.

50. Jaliliantabar F, Ghabodian B, Najafi C, Yusaf T (2018) Artificial neural network modelling sensitivity analysis of performance and emissions in a compression ignition engine using biodiesel fuel. Energies 11(9): 2410 .

51. Fadare DA (2010) The application of artificial neural networks to mapping of wind speed profile for energy application in Nigeria. Applied energy 87(3): 934-942.

Your next submission with Juniper Publishers will reach you the below assets

- Quality Editorial service

- Swift Peer Review

- Reprints availability

- E-prints Service

- Manuscript Podcast for convenient understanding

- Global attainment for your research

- Manuscript accessibility in different formats

( Pdf, E-pub, Full Text, Audio)

- Unceasing customer service

Track the below URL for one-step submission https://juniperpublishers.com/online-submission.php 